Research article

\title{
Bacterial community structure and removal performances in IFAS-MBRs: A pilot plant case study
}

\author{
Giorgio Mannina a , Marco Capodici a , Alida Cosenza ${ }^{a}$, Paolo Cinà ${ }^{\mathrm{b}}$, Daniele Di Trapani ${ }^{\mathrm{a},}{ }^{*}$, \\ Anna Maria Puglia ${ }^{\mathrm{b}}$, George A. Ekama ${ }^{\mathrm{c}}$ \\ a Dipartimento di Ingegneria Civile, Ambientale, Aerospaziale, dei Materiali, Università di Palermo, Viale delle Scienze, Ed. 8, 90100, Palermo, Italy \\ b Dipartimento di Scienze e Tecnologie Biologiche Chimiche e Farmaceutiche, Università di Palermo, Viale delle Scienze, Ed. 16, 90100, Palermo, Italy \\ ${ }^{\mathrm{c}}$ Water Research Group, Department of Civil Engineering, University of Cape Town, Rondebosch, 7700, Cape, South Africa
}

\section{A R T I C L E I N F O}

\section{Article history:}

Received 17 January 2017

Received in revised form

21 March 2017

Accepted 9 April 2017

\section{Keywords:}

Biological nutrients removal

WWTP

Membrane bioreactors

MBBR

Enhanced biological phosphorus removal IFAS-MBR

\begin{abstract}
A B S T R A C T
The paper reports the results of an experimental campaign carried out on a University of Cape Town (UCT) integrated fixed-film activated sludge (IFAS) membrane bioreactor (MBR) pilot plant. The pilot plant was analysed in terms of chemical oxygen demand (COD) and nutrients removal, kinetic/stoichiometric parameters, membrane fouling and sludge dewaterability. Moreover, the cultivable bacterial community structure was also analysed.

The pilot plant showed excellent COD removal efficiency throughout experiments, with average value higher than $98 \%$, despite the slight variations of the influent wastewater. The achieved nitrification efficiency was close to $98 \%$ for most of the experiments, suggesting that the biofilm in the aerobic compartment might have sustained the complete nitrification of the influent ammonia, even for concentrations higher than $100 \mathrm{mg} \mathrm{L}^{-1}$. The irreversible resistance due to superficial cake deposition was the mechanism that mostly affected the membrane fouling. Moreover, it was noticed an increase of the resistance due pore blocking likely due to the increase of the EPS ${ }_{\text {Bound }}$ fraction that could derive by biofilm detachment.

The bacterial strains isolated from aerobic tank are wastewater bacteria known for exhibiting efficient heterotrophic nitrification-aerobic denitrification and producing biofilm.
\end{abstract}

@ 2017 Elsevier Ltd. All rights reserved.

\section{Introduction}

Nutrients (particularly nitrogen, $\mathrm{N}$, and phosphorus, $\mathrm{P}$, compounds) may have adverse environmental impacts when discharged at high concentration (e.g., eutrophication, toxicity towards the aquatic organisms, etc.) (Wang et al., 2006). Therefore, nutrients abatement is an imperative requirement when discharging in sensitive areas (Li et al., 2013). In the last years, several biological and physic-chemical methods have been applied for nutrients removal from wastewater. Among these methods, biological treatments are the most cost-effective ones (Chu and Wang, 2011). Several investigations has been carried out in order to get useful insight on biological nutrient removal (BNR) (inter alia Wanner et al., 1992; Cosenza et al., 2013; Lu et al., 2015). BNR is operated thanks to the activity of autotrophic bacteria,

\footnotetext{
* Corresponding author

E-mail address: daniele.ditrapani@unipa.it (D. Di Trapani).
}

heterotrophic bacteria and polyphosphate-accumulating organisms (PAOs), under alternating anaerobic/anoxic/aerobic conditions (Naessens et al., 2012; Li et al., 2013). Traditionally, nitrogen removal is accomplished by the joint activity of ammonia oxidizing bacteria $(\mathrm{AOB})$ and nitrite oxidizing bacteria $(\mathrm{NOB})$ for nitrification, while heterotrophic organisms are responsible of denitrification. Biological phosphorus removal exploits PAOs ability to accumulate $P$ as intracellular polyphosphate under the alternation of anaerobic/ aerobic conditions. Although activated sludge are effective for removal of organic and nutrient compounds, the overall efficiency is strictly related to the performance of the solid-liquid separation phase into the final settler, which may suffer of separation problems (Wanner, 2002). In this context, membrane bioreactors (MBRs) may represent a useful solution, since they enable to disconnect the efficiency of the biological processes from the biomass settling properties. In particular, MBRs generally feature high quality effluent, small footprint and low sludge production rates compared to conventional activated sludge (CAS) systems 
(Stephenson et al., 2000; Mannina and Di Bella, 2012). Therefore, in the last years the integration of BNR process with MBRs has been proposed for wastewater treatment, in order to increase the effluent quality, including such BNR processes as University of Cape Town (UCT) process, anoxic/oxic (A/O) process and anaerobic/ anoxic/oxic (A2O) process (Hu et al., 2014). One of the major drawbacks in MBRs is still represented by fouling phenomena that may severely affect the filtration properties of the membrane modules (Judd and Judd, 2010). Particularly, the mixed liquor suspended solid (MLSS) concentration has been recognized to play a significant effect on membrane fouling (Poyatos et al., 2008; Di Trapani et al., 2014). An alternative to managing this problem is to couple a MBR system with a moving bed biofilm reactor (MBBR) in an IFAS mode (Integrated Fixed Film Activated Sludge). In this way, it enhances the simultaneous growth of suspended biomass and biofilm inside the system (Mannina et al., 2011), realizing a socalled moving bed membrane bioreactor (MBMBR) or MBBR-based integrated IFAS membrane bioreactor (IFAS-MBR) (Leyva-Díaz et al., 2013; Yang et al., 2014; Mannina et al., 2017). In particular, MBBR processes rely on the use of small plastic carrier elements that are kept in constant motion throughout the entire volume of the reactor, for biofilm growth (Ødegaard, 2006; Di Trapani et al., 2008, 2010). These systems are especially useful when slowly growing organisms as nitrifiers have to be maintained inside a wastewater treatment plant (WWTP) (Kermani et al., 2008). When combined with a MBR system realizing a MBMBR process, there is the potential to utilize best characteristics of both biofilm processes and membrane separation (Ivanovic and Leiknes, 2008). Using this technology, the biofilm system may reduce the concentration of suspended solids thus reducing the extent of membrane fouling. Nevertheless, IFAS-MBRs are relatively new, especially when referring to system performance, biomass biokinetic activity and membrane fouling tendency. Moreover, very few studies have been reported for BNR systems adopting hybrid IFAS-MBR processes (Yang et al., 2010). Literature reports that the successful of MBBR in carbon and nutrient removing is related to the cultivated bacteria community and functionality of the organisms that grow on the surface of the carriers and to their competition with suspended organisms (Biswas et al., 2014). Therefore, to better understand the performance of hybrid IFAS-MBR processes, it is necessary to study the microbial communities structure and enzyme activities both for biofilm and suspended organisms.

The aim of the present study is to gain insight about the behaviour of a University of Cape Town (UCT) pilot plant, combining both MBR and MBBR technology (UCT-IFAS-MBR), for the treatment of domestic wastewater. In particular, a UCT-IFASMBR pilot plant was monitored for two months without sludge withdrawals with the aim to investigate the system performance in terms of organic carbon and nutrients removal, biomass biokinetic behaviour, membrane fouling tendency and sludge features. Furthermore, the microbial communities' structure was also evaluated during experiments. The derived results are relevant also in view of the development of mathematical modelling tools for design and manage such systems (Freni et al., 2009; Mannina and Viviani, 2009).

\section{Material and methods}

\subsection{UCT-IFAS-MBR system description}

Three in-series reactors, anaerobic, anoxic and aerobic (volume equal to $62 \mathrm{~L}, 102 \mathrm{~L}$ and $211 \mathrm{~L}$, respectively) were realized in accordance with UCT lay-out (Ekama et al., 1983). An aerated MBR reactor (36 L) contained the ultrafiltration hollow fibre membrane (PURON $^{\circledR}$, courtesy of Koch Membrane Systems, Inc.). The mixed liquor recycled from the MBR to the anoxic reactor ( $\left.Q_{R A S}\right)$ was previously conveyed to a $40 \mathrm{~L}$ oxygen depletion reactor (ODR). The permeate extraction was replaced each $9 \mathrm{~min}$ by a minute of backwashing pumping a small volume of permeate through the membrane module from the Clean In Place (CIP) compartment. From the volumes of the reactors and recycle flows the mass fractions of the reactors were calculated from Ramphao et al. (2005) to be: anaerobic 0.071 , anoxic 0.232 , aerobic 0.481 , MBR + ODR 0.216 . The anoxic and aerobic compartments were filled with suspended plastic carriers (courtesy of Amitec Co. Ltd, carriers density $=0.95 \mathrm{~g} \mathrm{~cm}^{-3}$; carriers specific surface $=500 \mathrm{~m}^{2} \mathrm{~m}^{-3}$ ), with a 15 and $40 \%$ filling fraction, corresponding to a net surface area of 75 and $200 \mathrm{~m}^{2} \mathrm{~m}^{-3}$ in the anoxic and aerobic reactor, respectively. For the schematic layout of the UCT-IFAS-MBR pilot plant, the reader is referred to the literature (Mannina et al., 2017).

The permeate net flow rate was set equal to the inlet flow rate $20 \mathrm{~L} \mathrm{~h}^{-1}$ (QIN). In compliance with the UCT scheme, the recycle flows were set as follows: $Q_{R 1}=Q_{I N}$ from the anoxic to the anaerobic reactor; $\mathrm{Q}_{\mathrm{R} 2}=5$. $\mathrm{Q}_{\mathrm{N}}$ from the aerobic to the MBR reactor; $\mathrm{Q}_{\mathrm{RAS}}=4 \cdot \mathrm{Q}_{\mathrm{N}}$ from the MBR to the anoxic reactor.

The UCT-IFAS-MBR pilot plant was operated for 60 days and was fed with a mixture of real wastewater (deriving from the University buildings and characterized by higher ammonia content compared to typical domestic wastewater) and synthetic wastewater. The latter represented almost $50 \%$ of the total wastewater in terms of COD, with the $30 \%$ constituted by readily biodegradable COD (RBCOD) (dosed as sodium acetate), whilst the remaining 70\% was more slowly biodegradable (dosed as glycerol). The synthetic wastewater was spiked to meet the design organic loading rate to the pilot plant

The inlet wastewater had the following average features: $\mathrm{COD}=607 \mathrm{mg} \mathrm{L}^{-1}$; total nitrogen $(\mathrm{TN})=65 \mathrm{mg} \mathrm{L}^{-1}$; total phosphorus $(\mathrm{TP})=11 \mathrm{mg} \mathrm{L}^{-1}$ with a COD/TN/TP ratio of 100/10.7/1.8. The permeate flux was maintained equal to $21 \mathrm{~L} \mathrm{~m}^{-2} \mathrm{~h}^{-1}$, whereas the hydraulic retention time (HRT) was equal to $20 \mathrm{~h}$. The pilot plant was operated without sludge wasting during experiments; therefore, it was characterized by an increasing value (indefinite) of the mixed liquor sludge retention time (SRT). The average value of the liquid temperature $(\mathrm{T})$ and $\mathrm{pH}$ were $25^{\circ} \mathrm{C}$ and 7.8 , respectively. The dissolved oxygen (DO) concentrations (average values) ranged from $0.03 \mathrm{mg} \mathrm{L}^{-1}$ in the anaerobic compartment to 5.33 in the MBR compartment, respectively.

\subsection{Analytical methods}

During experiments, samples from inlet wastewater, permeate and from each reactor were collected in order to analyse total suspended solid (TSS) as well as volatile suspended solids (VSS) concentrations. Organic carbon content was assessed by total chemical oxygen demand ( $\left.\mathrm{COD}_{\mathrm{TOT}}\right)$, and supernatant $\mathrm{COD}\left(\mathrm{COD}_{\mathrm{SUP}}\right)$. Nitrogen forms (ammonium, nitrite and nitrate) and total nitrogen (TN) were assessed as well as orthophosphate and total phosphorus (TP). For further information regarding the analytical methods applied, the reader is addressed to Standard Methods (APHA, 2005). A multi-parameter probe provided the dissolved oxygen (DO) concentration as well as $\mathrm{pH}$ value in each reactor. Referring to the COD removal, both the biological removal and the total removal (after membrane filtration) were assessed according to Mannina et al. (2016a). Periodic tests on carrier samples were carried out, in order to evaluate the biofilm growth, in according to previously reported methods (Di Trapani et al., 2014).

Biokinetic parameters were measured by means of respirometric batch test carried out in accordance with Di Trapani et al. (2015). Moreover, ammonium and nitrate utilization rate (AUR and NUR respectively) were assessed by applying a modified 
protocol derived by Kristensen et al. (1992).

The extracellular polymeric substances (EPSs) produced by the bacterial metabolism were assessed throughout experiments, both soluble or SMP (soluble microbial product) and bound to the activated sludge flocs (EPS Bound $_{\text {) }}$ (Cosenza et al., 2013).

The fouling tendency of the membrane module was assessed by monitoring the total resistance $\left(\mathrm{R}_{\mathrm{T}}\right)$ to membrane filtration, and the specific fouling mechanisms have been assessed by applying the resistance-in-series (RIS) model (Di Trapani et al., 2014).

Two parameters were assessed in order to provide insight related to the sludge dewatering: capillary suction time (CST) and specific resistance to filtration (SRF) were measured in each reactor in agreement to Mannina et al. (2016a, b).

\subsection{Microbial communities structure}

\subsubsection{Isolation of microorganisms from anoxic and aerobic tanks}

In order to identify bacteria Activated sludge samples from the anoxic and aerobic tanks were plated at different dilutions, on Luria Bertami (LB), Mannitol Soya flour (MS) and R2YE agar-media (Kieser et al., 2000). The plates were incubated at $30{ }^{\circ} \mathrm{C}$ until appearance of microbial colonies ( $2-5$ days). The colonies, grown on the culture media and obtained from each sample, were selected on the basis of the morphology and pigmentation, and repeatedly incubated on agar-media to obtain pure cultures.

\subsubsection{Colony PCR of rDNA $16 S$ gene, BLAST alignment and phylogenetic analysis}

The microbial isolates were taxonomically characterized by their 16S rDNA sequence using the universal bacterial primers $27 \mathrm{~F}$ and 1492R (Frank et al., 2008) for 16S rDNA amplification by colony PCR as previously described (Milanesi et al., 2015). The PCR products were purified by using a GenElute Plasmid MiniPrep (Sigma-Aldrich, St Louis, USA). DNA sequencing was performed by BMR Genomics srl (Italy, http://www.bmr-genomics.it). The obtained 16S rRNA sequences were aligned with the reference GenBank sequences using the BLASTN tool of the NCBI website (McGinnis and Madden, 2004). Phylogenetic relationships to known species were inferred by both the neighbor-joining and the maximum likelihood methods using the software Mega6 (Tamura et al., 2013) with the aim to determine the most closely related specie. Two different phylogenetic trees were created for the isolates from anoxic and aerobic tanks, indicated as $\mathrm{AN}$ and $\mathrm{AE}$ respectively.

\section{Results and discussion}

\subsection{Organic carbon and nutrients removal rates}

Fig. 1 reports the trend of influent $\operatorname{COD}\left(\mathrm{COD}_{\mathrm{IN}}\right)$, supernatant of MBR (COD ${ }_{\text {SUP,MBR }}$ ) and effluent COD (COD OUT ) throughout experiments (Fig. 1a) as well as the COD removal efficiencies, expressed as total $\left(\eta_{\text {тот }}\right)$, biological $\left(\eta_{\text {віо }}\right)$ and physical contribution due to membrane filtration ( $\eta_{\text {PHYS }}$ ) (Fig. 1b). Fig. 1 also shows the pattern of inlet and permeate ammonia, effluent nitrate (Fig. 1c) as well as the achieved performance in terms of nitrification ( $\left.\eta_{\text {nit }}\right)$, denitrification ( $\left.\eta_{\text {denit }}\right)$ and nitrogen removal $\left(\eta N_{\text {total }}\right)$ (Fig. $\left.1 d\right)$.

The achieved results highlighted a very high total COD removal during the experiments, with average value higher than $98 \%$, despite the slight variations of the feeding COD. The biological COD removal, evaluated prior to membrane filtration also showed a satisfactory activity of the biological consortium, which includes the bacteria isolates, reaching an average value during experiments of $77 \%$. The above removal efficiency was slight higher compared to
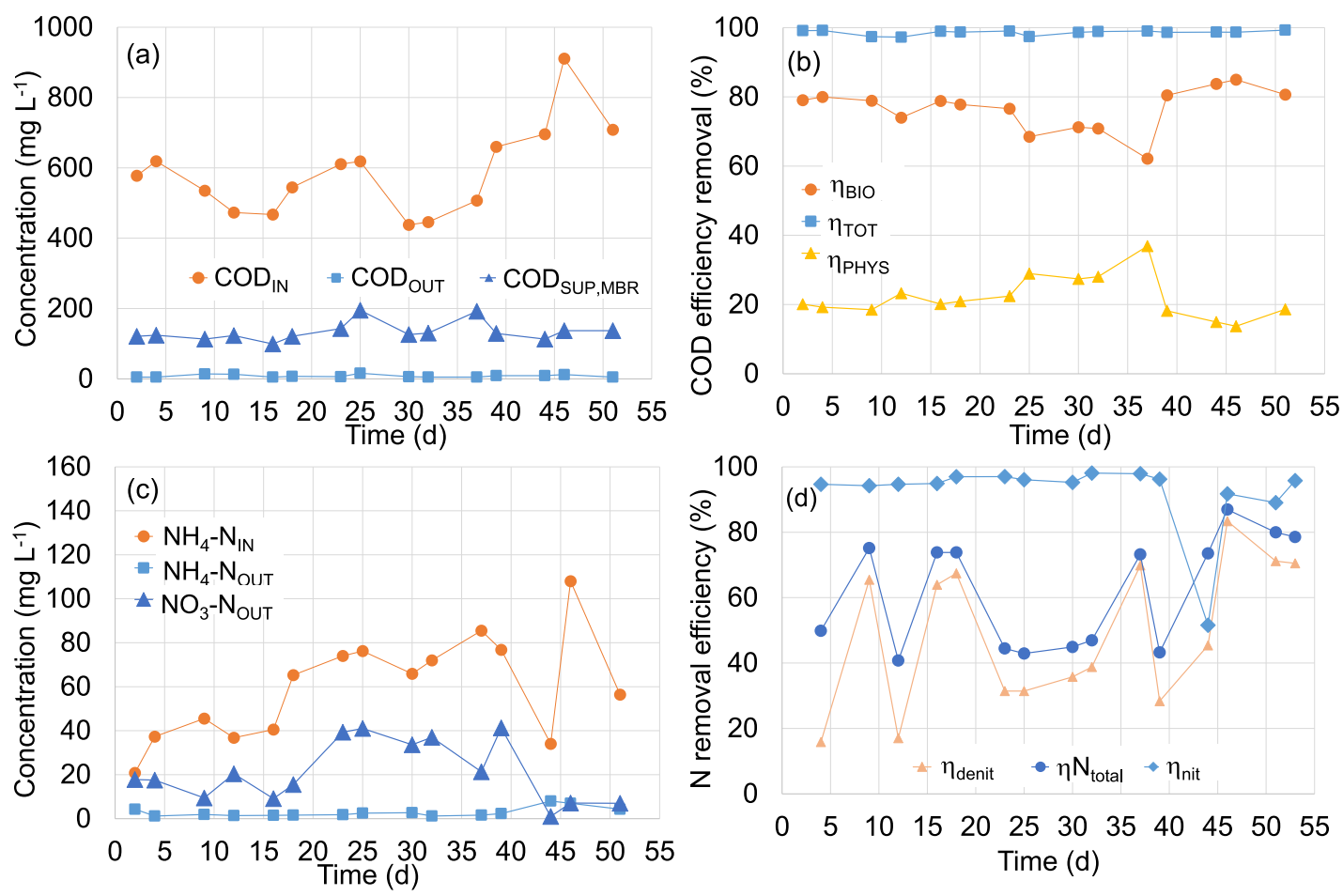

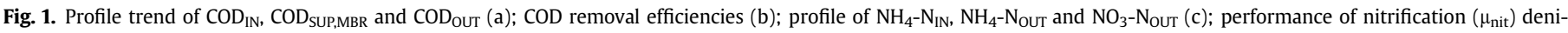
trification $\left(\mu_{\text {denit }}\right)$ and total nitrogen removal $\left(\mu \mathrm{N}_{\text {total }}\right)(\mathrm{d})$ during experiments. 
what was achieved by Leyva-Díaz et al. (2015), who found a COD removal efficiency close to $87 \%$ in a similar pilot plant. This difference could be explained by the fact that Leyva-Díaz et al. operated their system at much lower SRT, close to 11 days. The achieved results confirmed the robustness of MBR systems towards organic carbon removal.

The obtained results highlighted an excellent nitrification performance of the system, with efficiencies higher than $98 \%$ for most of the experiments, due to the presence of nitrifying strains isolated from the aerobic tank (Acinetobacter, Stenotrophomonas, Rhodococcus, Aeromonas and Escherichia genera). These genera are known for their nitrification ability (Xu et al., 2017). In particular, Acinetobacter strains isolated from the activated sludge of a coking wastewater treatment plant exhibited a huge ability to remove ammonium, nitrite and nitrate (Liu et al., 2015). A reduction in nitrification efficiency was noticed at day 44 ; however, this result is likely related to a sudden decrease of the inlet ammonia, due to the dilution effect of a rain event. Indeed, due to the specific composition of the feed wastewater, higher ammonia dilutions were observed during rain events.

It is worth noting that the system was able to guarantee high nitrification performances despite the increasing influent ammonia, up to $100 \mathrm{mg} \mathrm{L}^{-1}$. Due to the increasing mixed liquor SRT of the system (no MLSS wastage), the biofilm contribution towards nitrification was only moderate. Indeed, the AUR test carried on both activated sludge and biofilm revealed the higher nitrification ability of the suspended activated sludge. The nitrification rates were 1.33 and $0.38 \mathrm{mgNH}_{4}-\mathrm{N} \mathrm{g}^{-1} \mathrm{VSS} \mathrm{h}^{-1}$ for the suspended activated sludge and biofilm, respectively. The TN removal showed significant fluctuations during experiments, reaching an average value of $62 \%$. This result reflected the fluctuations of the denitrification efficiency during experiments. Nevertheless, the denitrification efficiency showed in general an increasing trend in the last experimental days, likely due to the contribution of biofilm growth as well as Bacillus genera (Verbaendert et al., 2011) into the anoxic compartment. The heterotrophic nitrification/aerobic denitrification ability of different Bacillus species was detected many years ago. For example, B. subtilis A1 was employed to treat highstrength urban wastewater and showed potential for industrial application (Yang et al., 2011). The TN removal efficiency was in good agreement with the results achieved by Leyva-Díaz and Poyatos (2015) on a similar pilot plant.

In Fig. 2 the profile of the influent and effluent $\mathrm{PO}_{4}-\mathrm{P}$ concentrations (Fig. 2a) are shown. Additionally, the assimilated or released $\mathrm{PO}_{4}-\mathrm{P}$ concentration inside the anaerobic and aerobic tanks is shown in Fig. $2 \mathrm{~b}$ and c, respectively. The average P removal efficiency was quite moderate, with average value close to $40.4 \%$. The low performance of the biological phosphorous removal could be due to the increase of the ammonium loading rate during experiments and the consequent decrease of the $\mathrm{C} / \mathrm{N}$ ratio value. Indeed, due to the moderate denitrification, the higher ammonium loading rate promoted an increased $\mathrm{NO}_{3}-\mathrm{N}$ production that was recycled from the anoxic to the anaerobic tank in the UCT scheme. This nitrate interferes with PAOs activity inside the anaerobic tank by preventing VFA generation from influent readily biodegradable organics, promoting instead the activity of denitrifying PAOs (DPAOs). Indeed, DPAOs have the capacity to grow under anoxic conditions with a very low rate using $\mathrm{NO}_{3}^{+}$and/or $\mathrm{NO}_{2}^{+}$as electron acceptor for $\mathrm{P}$ removal instead of oxygen, thus reducing the phosphorus removal efficiency (Hu et al., 2002; Parco et al., 2007). Moreover, when operating the system at high SRTs the competition for the available carbon source can hamper PAOs activity, thus decreasing the BioP removal efficiency (Ge et al., 2015).

\subsection{Biomass respiratory activity and biokinetic/stoichiometric parameters}

Respirometry was carried out for the assessment of the biomass activity throughout experiments by analyzing the main stoichiometric/kinetic parameters. Table 1 summarizes the values achieved
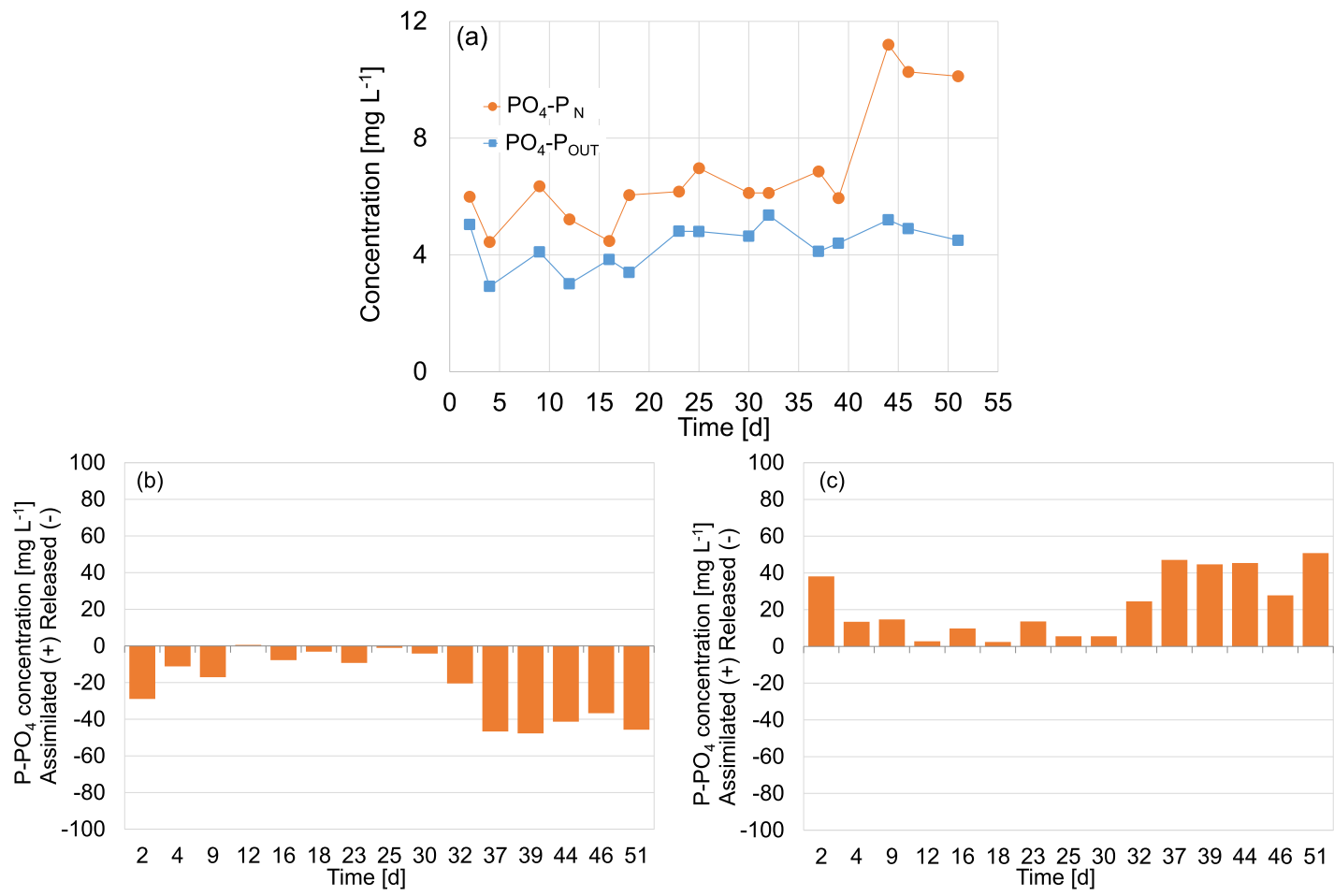

Fig. 2. Profile of the influent and effluent $\mathrm{PO}_{4}-\mathrm{P}$ concentration (a); $\mathrm{PO}_{4}-\mathrm{P}$ concentration released or assimilated inside the anaerobic (b) and aerobic tank (c). 
Table 1

Average values of kinetic and stoichiometric parameters throughout experiments, referring to suspended biomass and biofilm (in brackets the standard deviation values).

\begin{tabular}{lll}
\hline & Biomass & \\
\cline { 2 - 3 } & Activated sludge & Biofilm \\
\hline Heterotrophic & & \\
$\mathrm{Y}_{\mathrm{H}}\left[\mathrm{mgVSS} \mathrm{mg}^{-1} \mathrm{COD}\right]$ & $0.44( \pm 0.03)$ & $0.44( \pm 0.04)$ \\
$\mathrm{Y}_{\mathrm{STO}}\left[\mathrm{mgCOD} \mathrm{mg}^{-1} \mathrm{COD}\right]$ & $0.71( \pm 0.04)$ & $0.78( \pm 0.05)$ \\
$\mu_{\mathrm{H}, \mathrm{max}}\left[\mathrm{d}^{-1}\right]$ & $6.11( \pm 1.15)$ & $0.47( \pm 0.13)$ \\
$\mathrm{K}_{\mathrm{S}}\left[\mathrm{mgCOD} \mathrm{L}^{-1}\right]$ & $5.43( \pm 0.75)$ & $5.05( \pm 0.67)$ \\
$\mathrm{b}_{\mathrm{H}}\left[\mathrm{d}^{-1}\right]$ & $0.14( \pm 0.07)$ & - \\
SOUR $_{\max }\left[\mathrm{mgO}_{2} \mathrm{~g}^{-1} \mathrm{VSSh}^{-1}\right]$ & $19.82( \pm 4.10)$ & $1.73( \pm 0.46)$ \\
Autotrophic & & \\
$\mathrm{Y}_{\mathrm{A}}\left[\mathrm{mgVSS}_{\mathrm{mg}} \mathrm{mg}^{-1} \mathrm{~N}\right]$ & $0.17( \pm 0.04)$ & $0.31( \pm 0.20)$ \\
$\mu_{\mathrm{A}, \mathrm{max}}\left[\mathrm{d}^{-1}\right]$ & $0.23( \pm 0.06)$ & $0.17( \pm 0.10)$ \\
$\mathrm{K}_{\mathrm{NH}}\left[\mathrm{mgNH}_{4}-\mathrm{N} \mathrm{L}^{-1}\right]$ & $1.51( \pm 0.70)$ & $0.65( \pm 0.50)$ \\
Nitrif. Rate $\left.^{-1} \mathrm{mgNH}_{4} \mathrm{~L}^{-1} \mathrm{~h}^{-1}\right]$ & $3.45( \pm 1.63)$ & $1.10( \pm 0.87)$ \\
\hline
\end{tabular}

for both activated sludge and biofilm.

Concerning the suspended biomass, the measured parameters were in general consistent with literature results (Hauduc et al., 2011). The specific respiration rates $\left(\right.$ SOUR $\left._{\max }\right)$ and the maximum growth rates $\left(\mu_{\mathrm{H}, \mathrm{max}}\right)$ of heterotrophic species showed a moderate decreasing trend during experiments. This result was mainly related to the fact that the UCT-IFAS-MBR pilot plant was operated without sludge withdrawals, thus promoting a decrease in VSS "activity", the increase in suspended unbiodegradable VSS from the influent and endogenous respiration. Conversely, the increasing sludge age of the suspended consortium favored the development of slow growing microorganisms, like the nitrifying species, that showed an increasing pattern during experiments. Referring to the biofilm, it is worth noting that the autotrophic growth rate was higher compared to that of suspended biomass, highlighting the affinity of biofilm towards the nitrification process, despite the moderate biofilm growth observed in the present study. The significant activity of autotrophic species supported the high nitrification level of the system, as previously mentioned.

Furthermore, the occurrence of the storage phenomenon was observed in both suspended biomass and biofilm, related to the ability of specific microorganisms to rapidly convert the external organic substrate into internal storage products under dynamic conditions (Majone et al., 1999; Di Trapani et al., 2014).

\subsection{MLSS trend and biofilm growth}

Fig. 3 reports the pattern of suspended and attached biomass in the different compartments throughout experiments (Fig. 3a-d). From Fig. 3, it is possible to see a general increase of the suspended biomass concentration in the different compartments, related to the absence of sludge withdrawal. The biofilm showed a moderate development in both the anoxic and aerobic compartments. This result could be related to the competition between the suspended biomass and biofilm for the availability of the different substrates. In particular, biofilm detachment in the aerobic compartment was noticed after day 25 th with biofilm concentrations down to 0.4 gTS $\mathrm{L}^{-1}$. This behaviour could be related to a stress effect on the biofilm caused by the specific environmental conditions and should contribute to increase the membrane fouling of the system.

\subsection{EPS production}

Table 2 reports the values of EPS concentration during the experimental campaign, expressed as carbohydrates and proteins in microbial flocs (EPS Bound $_{\text {) }}$ and dissolved in the bulk liquid (SMP). By analyzing the data summarized in Table 2, it is worth noting that the SMP concentration was almost negligible compared to the

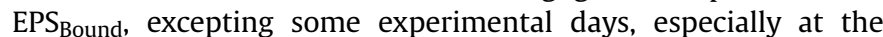
beginning of the experiments. On the other hand, the protein
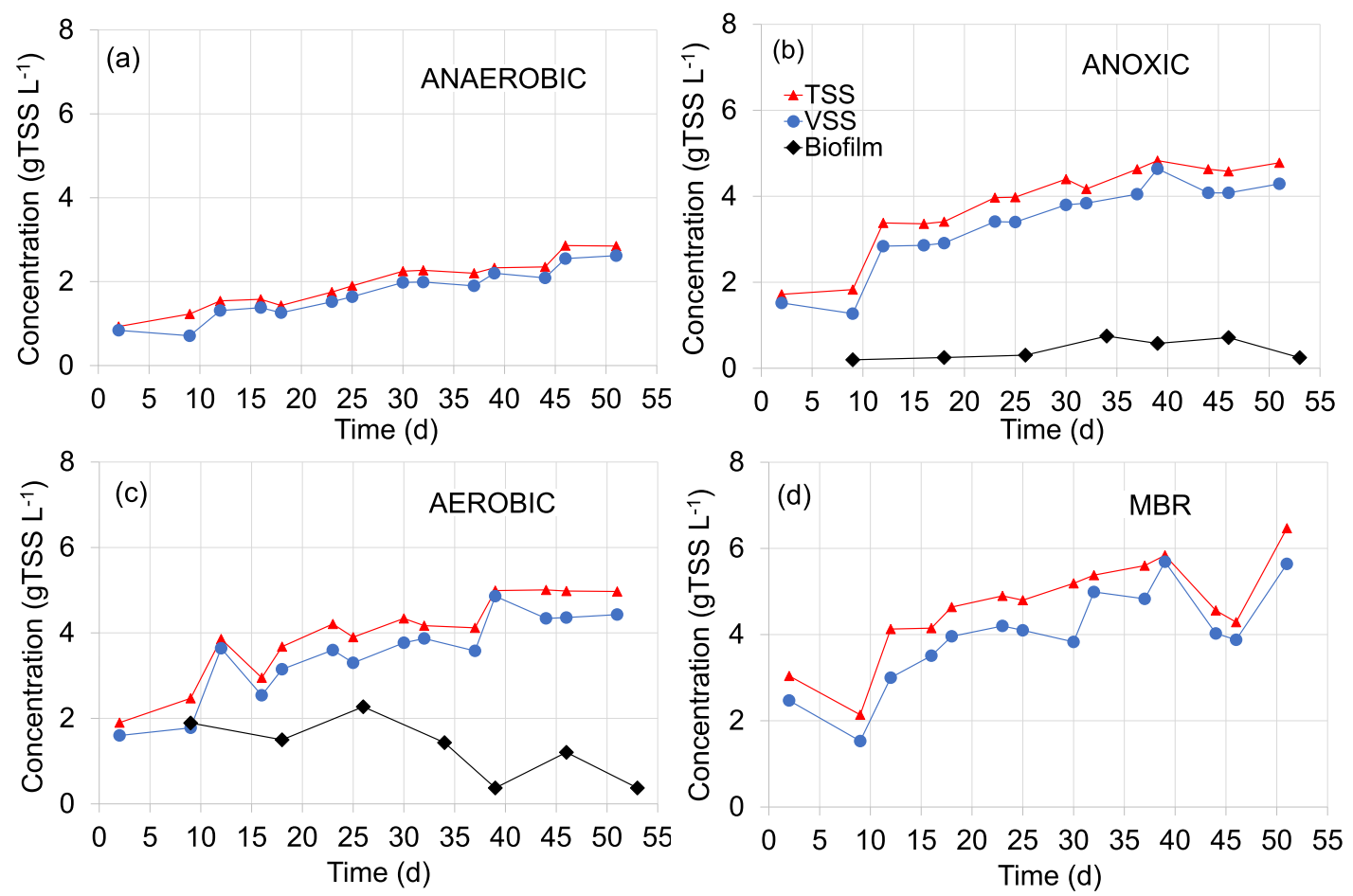

Fig. 3. Biomass trend during experiments, referring respectively to anaerobic (a), anoxic (b), aerobic (c) and MBR (d) compartment. 
Table 2

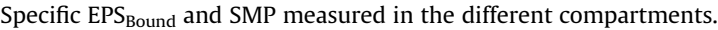

\begin{tabular}{|c|c|c|c|c|c|c|c|c|c|c|c|c|c|c|c|c|}
\hline \multirow[t]{3}{*}{ Day } & \multicolumn{4}{|c|}{ Anaerobic } & \multicolumn{4}{|l|}{ Anoxic } & \multicolumn{4}{|l|}{ Aerobic } & \multicolumn{4}{|l|}{ MBR } \\
\hline & $\mathrm{EPS}_{\mathrm{P}}$ & $\mathrm{EPS}_{\mathrm{C}}$ & $\mathrm{SMP}_{\mathrm{p}}$ & $\mathrm{SMP}_{\mathrm{C}}$ & $\mathrm{EPS}_{\mathrm{P}}$ & $\mathrm{EPS}_{\mathrm{C}}$ & $\mathrm{SMP}_{\mathrm{p}}$ & $\mathrm{SMP}_{\mathrm{C}}$ & $\mathrm{EPS}_{\mathrm{P}}$ & $\mathrm{EPS}_{\mathrm{C}}$ & $\mathrm{SMP}_{\mathrm{p}}$ & $\mathrm{SMP}_{\mathrm{C}}$ & $\mathrm{EPS}_{\mathrm{P}}$ & $\mathrm{EPS}_{\mathrm{C}}$ & $\mathrm{SMP}_{\mathrm{p}}$ & $\mathrm{SMP}_{\mathrm{C}}$ \\
\hline & \multicolumn{16}{|c|}{$\mathrm{mg} \mathrm{g}^{-1} \mathrm{TSS}$} \\
\hline 2 & 90.13 & 15.97 & 0.00 & 17.11 & 91.94 & 3.11 & 0.00 & 5.86 & 126.71 & 4.92 & 1.31 & 1.40 & 75.14 & 3.63 & 12.12 & 3.32 \\
\hline 9 & 85.84 & 0.00 & 52.70 & 97.10 & 121.37 & 78.69 & 34.11 & 28.31 & 83.75 & 48.88 & 4.87 & 1.91 & 69.86 & 0.00 & 14.55 & 63.75 \\
\hline 16 & 155.64 & 1.81 & 0.00 & 0.00 & 104.57 & 7.36 & 0.00 & 0.00 & 125.09 & 9.99 & 16.07 & 0.00 & 116.66 & 11.10 & 13.29 & 0.00 \\
\hline 23 & 135.39 & 5.25 & 3.32 & 0.00 & 120.86 & 11.65 & 6.86 & 1.97 & 116.16 & 13.22 & 0.00 & 4.32 & 116.05 & 14.80 & 16.79 & 4.07 \\
\hline 30 & 163.83 & 12.71 & 13.16 & 0.00 & 135.60 & 16.04 & 18.20 & 11.95 & 165.09 & 15.35 & 33.09 & 18.79 & 142.78 & 17.33 & 16.10 & 14.91 \\
\hline 37 & 180.72 & 15.71 & 21.64 & 0.00 & 169.75 & 24.31 & 0.00 & 0.00 & 170.25 & 24.24 & 0.00 & 0.00 & 180.54 & 23.94 & 12.85 & 0.00 \\
\hline 44 & 151.00 & 15.64 & 10.34 & 0.00 & 169.44 & 21.19 & 4.54 & 0.00 & 149.93 & 20.02 & 17.59 & 0.00 & 238.64 & 30.46 & 5.93 & 0.00 \\
\hline
\end{tabular}

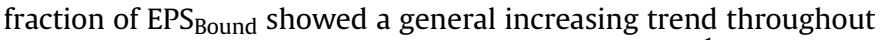
experiments, reaching values close to $250 \mathrm{mg} \mathrm{gTSS}^{-1}$ in the MBR compartment. Such values were higher compared to what was achieved in previous trials with UCT-MBR systems (Cosenza et al., 2013). This result could be related to biofilm detachment that might have increased the mixed liquor hydrophobicity, thus contributing to worsen the membrane filtration properties and compromising the filtration properties of the cake layer, as better outlined in section 3.5 .

\subsection{Sludge dewaterability}

The achieved results suggested that UCT-IFAS-MBR pilot plant was characterized by a reasonably good sludge dewaterability. The CST values were almost constant and slightly affected by the MLSS concentration, with average values of 15.27, 17.27, 15.07 and $18.93 \mathrm{~s}$ for the anaerobic, anoxic, aerobic and MBR compartment, respectively.

Furthermore, the low SRF values also confirmed the good sludge filtration properties, with average values for the different compartment close to $4 \times 10^{-12} \mathrm{~m} \mathrm{~kg}^{-1}$, significantly lower compared to what obtained by the same authors in previous experiences, when treating saline wastewater contaminated by hydrocarbons (Mannina et al., 2016b). Moreover, the activated sludge filterability was mostly influenced by the specific EPS ${ }_{\text {Bound }}$ concentration (i.e., referred to MLSS concentration). Fig. 4 shows the relationship between SRF and $\mathrm{EPS}_{\text {Bound }}$ inside each compartment.

\subsection{Membrane filtration properties}

Fig. 5 reports the profile of $\mathrm{R}_{\mathrm{T}}$ during experiments (Fig. $5 a$ ), the specific resistance contributions (Fig. 5b) as well as the correlation between specific resistance and EPS fractions (Fig. 5c1-c3). As noticeable from Fig. 6a, four extraordinary physical cleanings were carried out during experiments in order to prevent the TMP exceeding the critical values defined by the membrane manufacturer $(0.5-0.6$ bar). As depicted in Fig. 5b, the irreversible resistance due to superficial cake deposition $\left(\mathrm{R}_{\mathrm{C} \text {,irr }}\right)$ was the mechanism that mostly affected the membrane filtration properties. Moreover, it was noticed the increase of the resistance due to pore blocking $\left(\mathrm{R}_{\mathrm{PB}}\right)$ and a general worsening of the membrane filtration properties. This result could be due to the increase of the EPS Bound $_{\text {fraction }}$ that could be enhanced by biofilm detachment phenomena
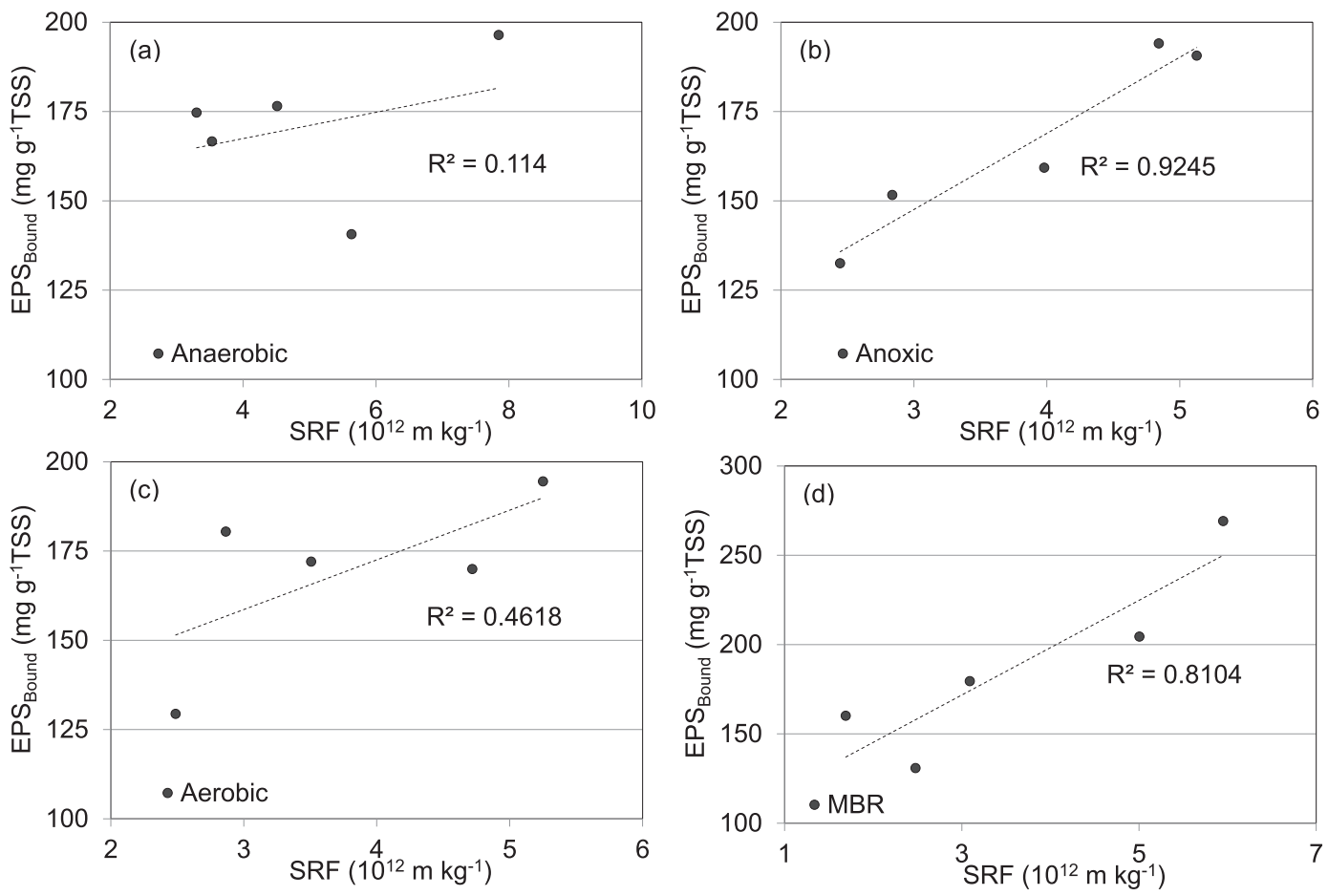

Fig. 4. Correlation between SRF and $\mathrm{EPS}_{\text {Bound }}$ inside the anaerobic (a), anoxic (b), aerobic (c) and MBR (d) reactor, respectively. 

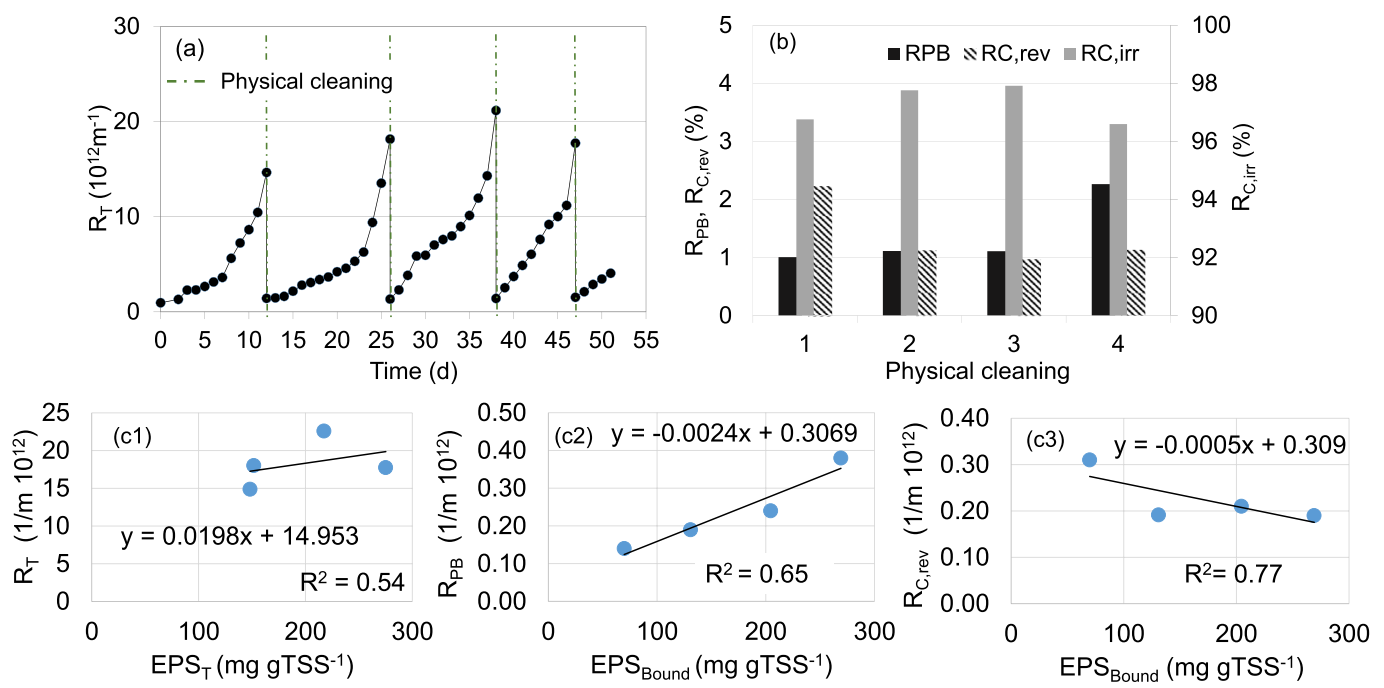

Fig. 5. Profile of total (a); and specific (b) resistances to filtration; correlation between $R_{T}$ and $E_{P S}(c 1)$, $R_{P B}$ and $E P S_{B o u n d}(c 2)$, $R_{C, r e v}$ and $E P S_{B o u n d}(c 3$ ).
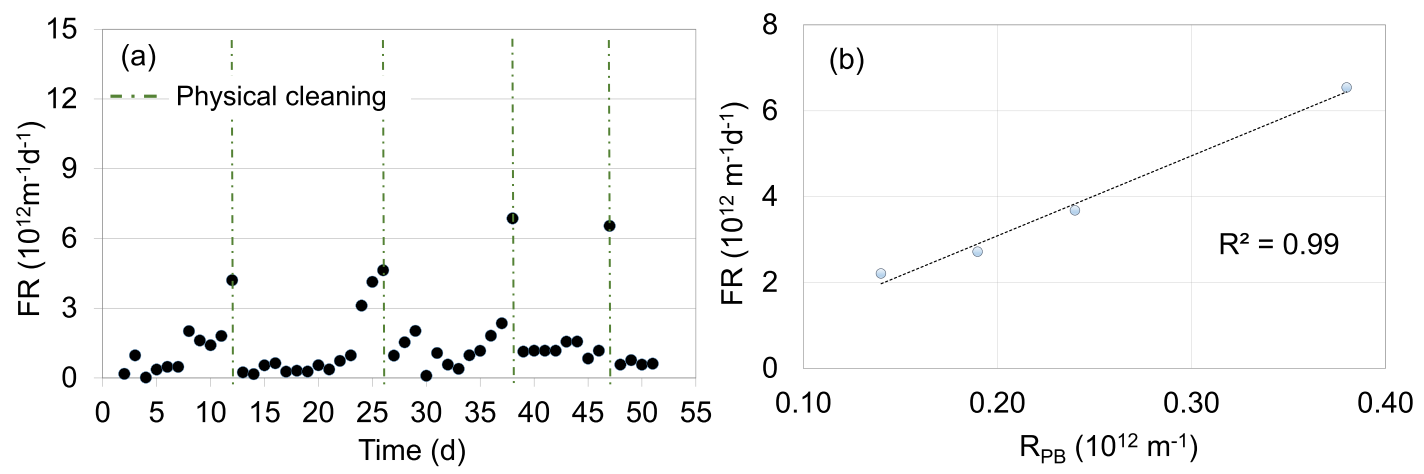

Fig. 6. FR trend during experiments (a) and relationship between FR and $\mathrm{R}_{\mathrm{PB}}$ before cleaning operations (b).

occurred during experiments.

The significant relationship that links EPS with the filtration properties of the system is depicted in the graphs reported in Fig. 5(c1-c3), where the main correlations between specific EPS fractions and resistance contributions are shown. According to the technical literature (Judd and Judd, 2010), when the concentration of EPS $\mathrm{T}$ in the mixed liquor increases, the membrane resistance increases as well, highlighting a worsening of the hydraulic performance of the system (see Fig. 5c1). Moreover, it is worth noting

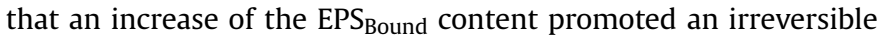
fouling mechanism, with the increase of the $\mathrm{R}_{\mathrm{PB}}$ (Fig. $5 \mathrm{c} 2$ ). On the other hand, the $R_{C, \text { rev }}$ significantly decreased with the increase of

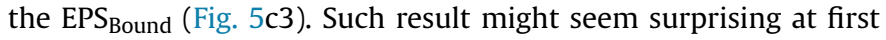
sight. However, it is in good agreement with the following considerations: the increase of protein content in the MBR compartment (as average), which is recognized to be the most hydrophobic fraction, determined a more "bloated" cake layer, similarly to what happens in the bulking phenomenon that occurs in CAS plants (Jenkins et al., 2003). Therefore, this situation significantly worsened the pre-filter effect of the cake layer (biological membrane). As a consequence, the foulants could reach more easily the internal pores of the membrane, thus promoting the increase of $R_{P B}$ (Fig. 5c2). Moreover, the biofilm detachment, rich in polymeric substances, could negatively affect the permeability of the cake layer, likely formed on the membrane surface, in agreement with previous findings (Di Trapani et al., 2014). The progressive worsening of the filtration properties was also confirmed by the fouling rate (FR) values (Fig. 6a). Indeed, the membrane showed a general increase of the fouling tendency, with average FR values (assessed between two subsequent cleaning operations) of 1.23,1.21, 1.65 and $1.81 \times 10^{12} \mathrm{~m}^{-1} \mathrm{~d}^{-1}$, respectively. Moreover, it was found that the FR values immediately before the cleaning operation (corresponding to the TMP "jump") were strongly correlated with the $R_{P B}$ (Fig. 6b). Therefore, despite the main fouling mechanism was the $\mathrm{R}_{C \text {,irr }}$, the sudden increase of the membrane fouling was strictly related to a pore clogging mechanism.

\subsection{Taxonomic diversity of cultivated bacteria collected from anoxic and aerobic tanks}

After 2-5 days of incubation, bacterial colonies appeared on the surface of agar-medium plates inoculated with activated sludge samples. A total of 14 isolates were selected and obtained as pure cultivations: in particular, 8 from aerobic tank (AE) and 6 from anoxic tank (AN), respectively. From all 14 isolates, a 16S rDNA sequence was obtained. All the sequences showed high similarities ( $\geq 99 \%$ ) with sequences obtained from NCBI database (Table 3 ).

The 16S rRNA gene sequences produced in this work and used 
Table 3

BLAST analysis of bacteria isolated from wastewater.

\begin{tabular}{|c|c|c|c|}
\hline Isolate name & Best BLAST hit(s) & Accession number & Sequence similarity (\%) \\
\hline AN_1 & Bacillus vallismortis strain NBRC 101236 & NR_113994.1 & 99 \\
\hline AN_2 & Bacillus toyonensis strain BCT-7112 & NR_121761.1 & 99 \\
\hline AN_3 & Bacillus cereus ATCC 14579 & NR_074540.1 & 99 \\
\hline AN_4 & Bacillus cereus ATCC 14579 & NR_074540.1 & 99 \\
\hline AN_5 & Bacillus toyonensis strain BCT-7112 & NR_121761.1 & 99 \\
\hline AN_6 & Bacillus vietnamensis strain NBRC 101237 & NR_113995.1 & 99 \\
\hline AE_1 & Escherichia fergusonii strain ATCC 35469 & NR_027549.1 & 99 \\
\hline AE_2 & Acinetobacter johnsonii strain ATCC 17909 & NR_117624.1 & 99 \\
\hline AE_3 & Acinetobacter johnsonii strain ATCC 17909 & NR_117624.1 & 100 \\
\hline AE_4 & Stenotrophomonas maltophilia strain ATCC 13637 & NR_112030.1 & 99 \\
\hline AE_5 & Aeromonas salmonicida strain ATCC 33658 & NR_118547.1 & 99 \\
\hline AE_6 & Rhodococcus jialingiae strain djl-6-2 & NR_115708.1 & 99 \\
\hline AE_7 & Brevundimonas vesicularis strain NBRC 12165 & NR_113586.1 & 100 \\
\hline AE_8 & Stenotrophomonas terrae strain R-32768 & NR_042569.1 & 99 \\
\hline
\end{tabular}

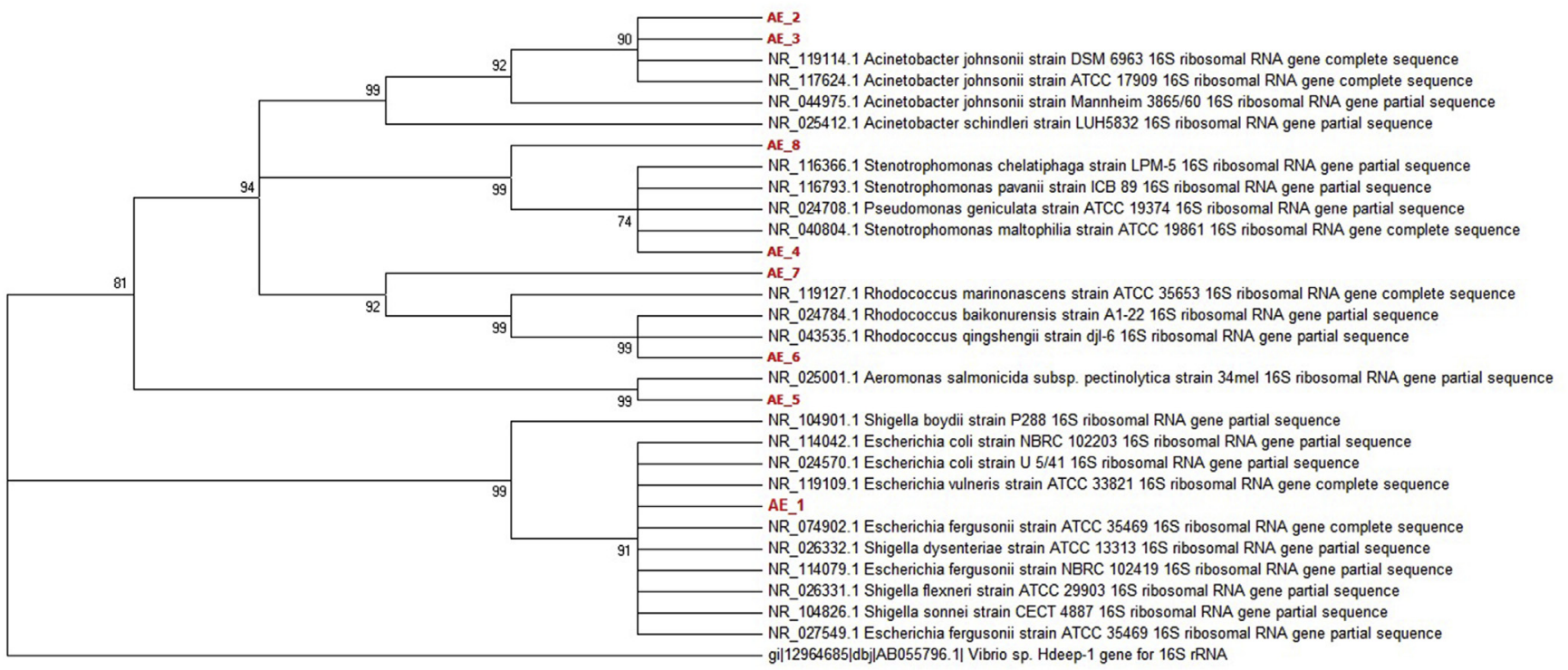

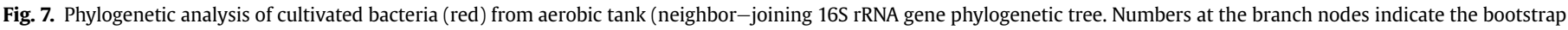

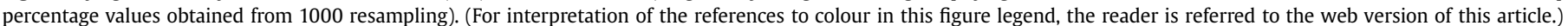

for the phylogenetic analysis were submitted to Genbank under the accession numbers KY321360 to KY321373. All the isolates from anoxic tank belonged to Bacillus genus. The isolates from aerobic tank belonged basically to six bacterial genera: Acinetobacter, Stenotrophomonas, Rhodococcus, Escherichia and Aeromonas.

Phylogenetic analysis confirmed the taxonomic affiliations retrieved by BLAST alignment; as an example, Fig. 7 shows the phylogenetic analysis of cultivated bacteria from the aerobic tank, whilst the phylogenetic analysis from the anoxic tank is provided as supplementary material (Fig. S1). Bacilli isolated from anoxic tank are facultative bacteria capable of growing with nitrate or nitrite as electron acceptor or growing by fermentation in the absence of oxygen (Ji et al., 2016). Moreover, the isolates related to B. toyonensis could exhibit flocculating activity (Okaiyeto et al., 2015). All strains isolated from aerobic tank are wastewater bacteria known for exhibiting efficient heterotrophic nitrification-aerobic denitrification ability at a wide range of ammonium loads and producing biofilm (Di Bonaventura et al., 2004; Wang et al., 2010; Chen et al., 2012; Ren et al., 2014).

\section{Conclusions}

The results of this study confirmed a very high COD and nitrification performance in the UCT-IFAS-MBR system. Conversely, the average $P$ removal efficiency was moderate, likely due to the high SRT of the activated sludge. The irreversible resistance due to superficial cake deposition mostly affected the membrane filtration. Metagenomic analysis is useful to shed light on the overall composition of the bacterial communities essential to remove nutrients in this system. As final remark, the UCT-IFAS-MBR showed great potentiality; nevertheless, from the findings of the study it is suggested to reduce the SRT to improve the biological phosphorus removal, while leaving the nitrification burden to the biofilm.

\section{Acknowledgments}

This work forms part of a research project supported by grant of the Italian Ministry of Education, University and Research (MIUR) through the Research project of national interest PRIN2012 (D.M. 28 dicembre 2012 n. 957/Ric - Prot. 2012PTZAMC) entitled "Energy consumption and GreenHouse Gas (GHG) emissions in the wastewater treatment plants: a decision support system for planning and management - http://ghgfromwwtp.unipa.it" in which the first author is the Principal Investigator. 
Appendix A. Supplementary data

\section{Supplementary data related to this article can be found at http://} dx.doi.org/10.1016/j.jenvman.2017.04.031.

\section{References}

APHA, 2005. Standard Methods for the Examination of Water and Wastewater. APHA, AWWA and WPCF, Washington DC, USA.

Biswas, K., Taylor, M.W., Turner, S.J., 2014. Successional development of biofilms in moving bed biofilm reactor (MBBR) systems treating municipal wastewater. Appl. Microbiol. Biotechnol. 98 (3), 1429-1440.

Chen, P., Li, J., Li, Q.X., Wang, Y., Li, S., Ren, T., Wang, L., 2012. Simultaneous heterotrophic nitrification and aerobic denitrification by bacterium Rhodococcus sp. CPZ24. Bioresour. Technol. 116 (2), 266-270.

Chu, L., Wang, J., 2011. Comparison of polyurethane foam and biodegradable polymer as carriers in moving bed biofilm reactor for treating wastewater with a low C/N ratio. Chemosphere 83, 63-68.

Cosenza, A., Di Bella, G., Mannina, G., Torregrossa, 2013. The role of EPS in fouling and foaming phenomena for a membrane bioreactor. Bioresour. Technol. 147, $184-192$.

Di Bonaventura, G., Spedicato, G., D'Antonio, D., Robuffo, I., Piccolomini, R., 2004. Biofilm formation by Stenotrophomonas maltophilia: modulation by quinolones, trimethoprim-sulfamethoxazole, and ceftazidime. Antimicrob. Agents Chemother 48 (8), 151-160.

Di Trapani, D., Mannina, G., Torregrossa, M., Viviani, G., 2008. Hybrid moving bed biofilm reactors: a pilot plant experiment. Water Sci. Technol. 57 (10), 1539-1545.

Di Trapani, D., Mannina, G., Torregrossa, M., Viviani, G., 2010. Quantification of kinetic parameters for heterotrophic bacteria via respirometry in a hybrid reactor. Water Sci. Technol. 61 (7), 1757-1766.

Di Trapani, D., Di Bella, G., Mannina, G., Torregrossa, M., Viviani, G., 2014. Comparison between moving bed-membrane bioreactor (MB-MBR) and membrane bioreactor (MBR) systems: influence of wastewater salinity variation. Bioresour. Technol. 162, 60-69.

Di Trapani, D., Di Bella, G., Mannina, G., Torregrossa, M., Viviani, G., 2015. Effect of C/ $\mathrm{N}$ shock variation on the performances of a moving bed membrane bioreactor. Bioresour. Technol. 189, 250-257.

Ekama, G.A., Siebritz, I.P., Marais, G.R., 1983. Considerations in the process design of nutrient removal activated sludge processes. Water Sci. Technol. 15 (3-4), $283-318$.

Frank, J.A., Reich, C.I., Sharma, S., Weisbaum, J.S., Wilson, B.A., Olsen, G.J., 2008. Critical evaluation of two primers commonly used for amplification of bacterial 16S rRNA genes. Appl. Environ. Microbiol. 74, 2461-2470.

Freni, G., Mannina, G., Viviani, G., 2009. Assessment of data availability influence on integrated urban drainage modelling uncertainty. Environ. Model. Softw. 24 (10), 1171-1181.

Ge, H., Batstone, D.J., Keller, J., 2015. Biological phosphorus removal from abattoir wastewater at very short sludge ages mediated by novel PAO clade Comamonadaceae. Water Res. 69, 173-182.

Hauduc, H., Rieger, L., Ohtsuki, T., Shaw, A., Takács, I., Winkler, S., Héduit, A., Vanrolleghem, P.-A., Gillot, S., 2011. Activated sludge modelling: development and potential use of a practical applications database. Water Sci. Technol. 63, 2164-2182.

Hu, Z.-R., Wentzel, M.C., Ekama, G.A., 2002. The significance of denitrifying polyphosphate accumulating organisms in biological nutrient removal activated sludge systems. Water Sci. Technol. 46 (1/2), 129-138.

Hu, X., Xie, L., Shim, H., Zhang, S., Yang, D., 2014. Biological nutrient removal in a full scale anoxic/anaerobic/aerobic/pre-anoxic-MBR plant for low $\mathrm{C} / \mathrm{N}$ ratio municipal wastewater treatment. Chin. J. Chem. Eng. 22 (4), 447-454.

Ivanovic, I., Leiknes, T., 2008. Impact of aeration rates on particle colloidal fraction in the biofilm membrane bioreactor (BF-MBR). Desalination 231 (1-3), 182-190.

Jenkins, D., Richard, M.G., Daigger, G.T., 2003. Manual on the Causes and Control of Activated Sludge Bulking, Foaming and Other Solids Separation Problems. IWA Publishing, London.

Ji, B., Chen, W., Zhu, L., Yang, K., 2016. Isolation of aluminum-tolerant bacteria capable of nitrogen removal in activated sludge. Mar. Pollut. Bull. 106 (1-2), $31-34$.

Judd, S.J., Judd, C., 2010. Principles and Applications of Membrane Bioreactors in Water and Wastewater Treatment, second ed. Elsevier, London, UK.

Kermani, M., Bina, B., Movahedian, H., Ami, M.M., Nikaein, M., 2008. Application of moving bed biofilm process for biological organics and nutrients removal from municipal wastewater. Am. J. Environ. Sci. 4 (6), 675-682.

Kieser, Y., Bibb, M.J., Buttner, M.J., Chater, K.F., Hopwood, D.A., 2000. Practical Streptomyces Genetics. The John Innes Foundation, Norwich, UK.

Kristensen, G.H., Jørgensen, P.E., Henze, M., 1992. Characterization of functional microorganism groups and substrate in activated sludge and wastewater by AUR, NUR and OUR. Water Sci. Technol. 25, 43-57.

Leyva-Díaz, J.C., Poyatos, J.M., 2015. Start-up of membrane bioreactor and hybrid moving bed biofilm reactor-membrane bioreactor: kinetic study. Water Sci. Technol. 72 (11), 1948-1953.

Leyva-Díaz, J.C., Calderón, K., Rodríguez, F.A., González-López, J., Hontoria, E., Poyatos, J.M., 2013. Comparative kinetic study between moving bed biofilm reactor-membrane bioreactor and membrane bioreactor systems and their influence on organic matter and nutrients removal. Biochem. Eng. J. 77, 28-40.

Leyva-Díaz, J.C., González-Martínez, A., González-López, J., Muñío, M.M. Poyatos, J.M., 2015. Kinetic modeling and microbiological study of two-step nitrification in a membrane bioreactor and hybrid moving bed biofilm reactor-membrane bioreactor for wastewater treatment. Chem. Eng. J. 259, $692-702$.

Li, C., Wang, T., Zheng, N., Zhang, J., Ngo, H.H., Guo, W., Liang, S., 2013. Influence of organic shock loads on the production of $\mathrm{N}_{2} \mathrm{O}$ in denitrifying phosphorus removal process. Bioresour. Technol. 141, 160-166.

Liu, Y.X., Hu, T., Song, Y., Chen, H., Lv, Y.K., 2015. Heterotrophic nitrogen removal by Acinetobacter sp. Y1 isolated from coke plant wastewater. J. Biosci. Bioeng. 120 (5), 549-554.

Lu, Q., Wu, H., Li, H., Yang, D., 2015. Enhanced biological nutrient removal in modified carbon source division anaerobic anoxic oxic process with return activated sludge preconcentration. Chin. J. Chem. Eng. 23, 1027-1034.

Majone, M., Dircks, K., Beun, J.J., 1999. Aerobic storage under dynamic conditions in activated sludge processes. The state of the art. Water Sci. Technol. 39, 61-73.

Mannina, G., Viviani, G., 2009. Separate and combined sewer systems: a long-term modelling approach. Water Sci. Technol. 60 (3), 555-565.

Mannina, G., Di Trapani, D., Viviani, G., Ødegaard, H., 2011. Modelling and dynamic simulation of hybrid moving bed biofilm reactors: model concepts and application to a pilot plant. Biochem. Eng. J. 56 (1-2), 23-36.

Mannina, G., Di Bella, G., 2012. Comparing two start-up strategies for MBRs: experimental study and mathematical modelling. Biochem. Eng. J. 68, 91-103.

Mannina, G., Capodici, M., Cosenza, A., Di Trapani, D., 2016a. Carbon and nutrient biological removal in a University of Cape Town membrane bioreactor: analysis of a pilot plant operated under two different C/N ratios. Chem. Eng. J. 296, 289-299.

Mannina, G., Cosenza, A., Di Trapani, D., Capodici, M., Viviani, G., 2016b. Membrane bioreactors for treatment of saline wastewater contaminated by hydrocarbons (diesel fuel): an experimental pilot plant case study. Chem. Eng. J. 291 (1), 269-278.

Mannina, G., Capodici, M., Cosenza, A., Di Trapani, D., Laudicina, V.A., Ødegaard, H. 2017. Nitrous oxide from moving bed based integrated fixed film activated sludge membrane bioreactors. J. Environ. Manag. 187, 96-102.

McGinnis, S., Madden, T.L., 2004. BLAST: at the core of a powerful and diverse set of sequence analysis tools. Nucleic Acids Res. 32 (Suppl. 2), W20-W25.

Milanesi, C., Cresti, M., Costantini, L., Gallo, M., Gallo, G., Crognale, S., Faleri, C., Gradi, A., Baldi, F., 2015. Spoilage of oat bran by sporogenic microorganisms revived from soil buried 4000 years ago in Iranian archaeological site. Int. Biodeter. Biodegr 104, 83-91.

Naessens, W., Maere, T., Nopens, I., 2012. Critical review of membrane bioreactor models - Part 1: biokinetic and filtration models. Bioresour. Technol. 122, 95-106.

Ødegaard, H., 2006. Innovations in wastewater treatment: the moving bed biofilm process. Water Sci. Technol. 53, 17-33.

Okaiyeto, K., Nwodo, U.U., Mabinya, L.V., Okoh, A.I., 2015. Bacillus toyonensis strain AEMREG6, a bacterium isolated from South African marine environment sediment samples produces a glycoprotein bioflocculant. Molecules 20 (3), 5239-5259.

Parco, V., du Toit, G., Wentzel, M., Ekama, G.A., 2007. Biological nutrient removal in membrane bioreactors: denitrification and phosphorus removal kinetics. Water Sci. Technol. 56 (6), 125-134.

Poyatos, J.M., Molina-Muñoz, M.A., Delgado, F., González-López, J., Hontoria, E., 2008. Flux influence on membrane fouling in a membrane bioreactor system under real conditions with urban wastewater. J. Environ. Sci. Health A. 43 (14) 1685-1691.

Ramphao, M., Wentzel, M.C., Merritt, R., Ekama, G.A., Young, T., Buckley, C.A., 2005 Impact of membrane solid-liquid separation on design of biological nutrient removal activated sludge systems. Biotechnol. Bioeng. 89 (6), 630-646.

Ren, Y.X., Yang, L., Liang, X., 2014. The characteristics of a novel heterotrophic nitrifying and aerobic denitrifying bacterium, Acinetobacter junii YB. Bioresour Technol. 171, 1-9.

Stephenson, T., Judd, S.J., Jefferson, B., Brindle, K., 2000. Membrane Bioreactors for Wastewater Treatment. IWA Publishing, London, UK.

Tamura, K., Stecher, G., Peterson, D., Filipski, A., Kumar, S., 2013. MEGA6: molecular evolutionary genetics analysis version 6.0. Mol. Biol. Evol. 30, 2725-2729.

Verbaendert, I., Boon, N., De Vos, P., Heylen, K., 2011. Denitrification is a common feature among members of the genus Bacillus. Syst. Appl. Microbiol. 34, 385-391.

Wang, X.J., Xia, S.Q., Chen, L., Zhao, J.F., Renault, N.J., Chovelon, J.M., 2006. Nutrients removal from municipal wastewater by chemical precipitation in a moving bed biofilm reactor. Process Biochem. 41 (4), 824-828.

Wang, Z., Xu, J., Li, Y., Wang, K., Wang, Y., Hong, Q., Li, W.J., Li, S.P., 2010. Rhodococcus jialingiae sp. nov., an actinobacterium isolated from sludge of a carbendazim wastewater treatment facility. Int. J. Syst. Evol. Microbiol. 60, 378-381.

Wanner, J., 2002. Control of filamentous bulking in activated sludge. In: Bitton, G. (Ed.), Encyclopedia of Environmental Microbiology. John Wiley \& Sons Inc, New York USA, pp. 1306-1315.

Wanner, J., Cech, J.S., Kos, M., 1992. New process design for biological nutrient removal. Water Sci. Technol. 25 (4-5), 445-448.

Xu, Y., He, T., Li, Z., Ye, Q., Chen, Y., Xie, E., Zhang, X., 2017. Nitrogen removal characteristics of Pseudomonas putida Y-9 capable of heterotrophic nitrification and aerobic denitrification at low temperature. Hindawi Publishing Corporation 
BioMed Res. Int. 2017. Article ID 1429018.

Yang, S., Yang, F., Fu, Z., Wang, T., Lei, R., 2010. Simultaneous nitrogen and phosphorus removal by a novel sequencing batch moving bed membrane bioreactor for wastewater treatment. J. Hazard. Mat. 175, 551-557.

Yang, X.P., Wang, S.M., Zhang, D.W., Zhou, L.X., 2011. Isolation and nitrogen removal characteristics of an aerobic heterotrophic nitrifying-denitrifying bacterium,
Bacillus subtilis A1. Bioresour. Technol. 102 (2), 854-862.

Yang, W. Syed, W., Zhou, H., 2014. Comparative study on membrane fouling between membrane-coupled moving bed biofilm reactor and conventional membrane bioreactor for municipal wastewater treatment. Water Sci. Technol. 69, 1021-1027. 